\title{
No differences in infections between patient-specific implants and conventional mini-plates in mandibular bilateral sagittal split osteotomy - Up to 3-year follow-up
}

\author{
Juho Suojanen a, b, *, Sanna Järvinen ${ }^{c}$, Zlatan Hodzic ${ }^{c}$, Justus Reunanen ${ }^{\mathrm{d}}$, Junnu Leikola ${ }^{\mathrm{a}}$, \\ Patricia Stoor $^{\mathrm{c}}$ \\ ${ }^{a}$ Department of Plastic Surgery, Cleft Palate and Craniofacial Centre, (Head: Hannu Kuokkanen), Helsinki University Central Hospital, Helsinki, Finland \\ ${ }^{\mathrm{b}}$ Päijät-Häme Joint Authority for Health and Wellbeing, Department of Oral and Maxillo-Facial Surgery, (Head: Eeva Kormi), Lahti, Finland \\ ${ }^{c}$ Department of Oral and Maxillo-Facial Diseases, Clinicum, Faculty of Medicine, (Head: Risto Kontio), University of Helsinki and Helsinki University Central \\ Hospital, Helsinki, Finland \\ ${ }^{\mathrm{d}}$ Cancer and Translational Medicine Research Unit, Biocenter Oulu, (Head: Johanna Myllyharju), University of Oulu, Oulu, Finland
}

\section{A R T I C L E I N F O}

\section{Article history:}

Paper received 9 July 2018

Accepted 15 October 2018

Available online $\mathrm{xxx}$

\section{Keywords:}

Bilateral sagittal split osteotomy

BSSO

Orthognathic surgery

Patient-specific implant

CAD/CAM

Postoperative infection

\begin{abstract}
A B S T R A C T
The use of individually designed osteotomies, combined with individually manufactured osteosynthesis material, is rapidly becoming a standard for more challenging maxillofacial surgery. The benefits of patient-specific implants (PSI) in orthognathic surgery are clear in complex cases. PSIs can enhance precision and ease up the surgical protocol. We previously reported on the benefits of PSIs as reposition and fixation systems during Le Fort I osteotomy. The aim of this study was to evaluate a cohort of 28 patients, treated with bilateral sagittal split osteotomy (BSSO) and PSIs for fixation, with regard to healing for up to 3 years. A retrospective cohort of 48 patients with conventional mini-plate repositioned mandibles was also collected for statistical analysis. No statistically significant differences were found with regard to infection, soft tissue problems, or reoperations between these two groups.
\end{abstract}

() 2018 European Association for Cranio-Maxillo-Facial Surgery. Published by Elsevier Ltd. All rights reserved.

\section{Introduction}

The use of virtual design for osteotomies and surgical movement of the jaws is rapidly becoming a common practice in orthognathic surgery. Individually manufactured surgical tools, such as drill and cutting guides as well as patient-specific implants (PSI) for osteosynthesis, will soon be available to all clinicians. As computer-aided design and manufacturing (CAD/CAM) has developed, the creation of more sophisticated and freely designed implants has become possible (Gander et al., 2015; Mazzoni et al., 2015; Suojanen et al., 2016, 2017). Most of the systems use either CAD/CAM-generated wafers or provide patient-specific saw and drill guides, together with custom-made titanium implants.

Individually manufactured implants, combined with the use of drill guides, also make wafer-free positioning of bone segments

\footnotetext{
* Corresponding author. Department of Plastic Surgery, Cleft Palate and Craniofacial Centre, Helsinki University Central Hospital, P.O. Box 226, 00029 HUS, Finland.

E-mail address: juho.suojanen@helsinki.fi (J. Suojanen).
}

possible. This has been proven to be successful in Le Fort I osteotomy (Suojanen et al., 2017; Heufelder et al., 2017). However, in mandibular bilateral sagittal split osteotomy (BSSO) the drill guide combined with the PSI does not seem to be reliable enough to be used alone without wafer support (Suojanen et al., 2017). The use of PSIs in the mandible should, however, be considered in the most complex cases, where there is significant asymmetry in the ramus height or shape of the mandible. PSIs provided by companies are commonly manufactured either by milling from titanium monoblocks or by laser sintering from titanium powder. The individually designed implants often follow the contours of the underlying bone with high fidelity, which is beneficial, especially in the maxilla. However, the benefits of PSIs with regard to final positioning and stability during BSSO are not yet as clear (Suojanen et al., 2017). To date, no follow-up data on PSIs used in BSSO osteosynthesis exist.

In this study we report data with regard to complications, such as infection, soft tissue problems, or reoperations, during a followup of up to 3 years in a cohort of 28 patients treated with BSSO and PSIs. For a comparison of the postoperative complications mentioned above, a retrospective cohort of 48 patients treated with BSSO and conventional mini-plate fixation was collected. 


\section{Materials and methods}

In both the PSI and mini-plate groups the osteotomies were designed and performed according to Epker (1977), cutting straight through the mandibular bodies at the caudal part of the inferior mandibular border. Both mini-plates and PSIs were designed or adjusted to the lateral border of the mandibular ramus at the level of the molar root apexes. PSI drill holes were designed to avoid the roots and mandibular nerve despite only monocortical screws being used.

This cohort of PSI patients $(n=28)$ was previously reported in more detailed (Suojanen et al., 2017). Briefly, all PSI patients underwent a traditional BSSO, during which drill guides were used to predrill the holes for osteosynthesis with PSIs, using the Planmeca ProModel (Planmeca Ltd, Helsinki, Finland). The PSIs were milled from titanium alloy to a thickness of $0.8-1.0 \mathrm{~mm}$ and prepared for drill holes comparable to Matrix Orthognathic Gold mini-plates. Three screw holes were designed on both sides for vertical osteotomy. Monocortical non-locking 6-8 $\mathrm{mm}$ Synthes Orthognathic screws (diameter $1.85 \mathrm{~mm}$ ) were used for each patient. PSIs were designed for similar location on the mandible lateral border to conventional miniplates. Short advancements were performed with one interconnecting bridge and longer advancements with two bridges (Fig. 1).

The follow-up data for the PSI group were collected from the Helsinki University Hospital patient archives up to February 28,
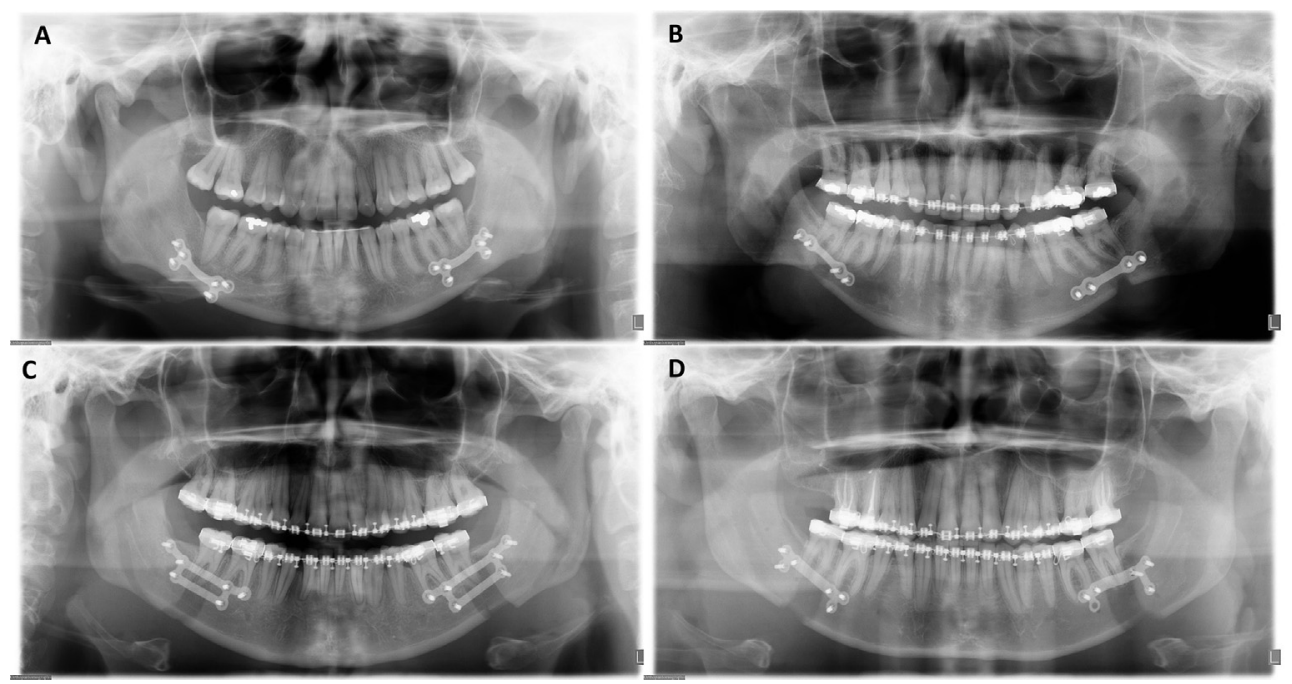

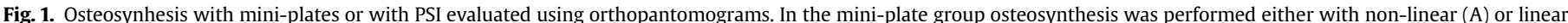

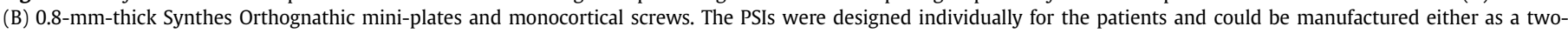

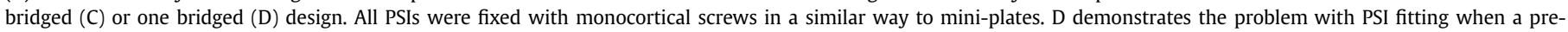
designed drill whole becomes too loose for the screw: one of the left-side drill holes remained unused.

Table 1

BSSO patients operated with PSI.

\begin{tabular}{|c|c|c|c|c|c|c|}
\hline Patient & Gender & Age & Diagnosis 1 & Diagnosis 2 & Wound problems, complications or reoperations & Follow-up (mo) \\
\hline 1 & $\mathrm{~F}$ & 43 & Deep bite & Retrognathia mnd & Wound infection left side $1 \mathrm{wk}$ postop, PSI removal 4 mo & 38 \\
\hline 2 & $\mathrm{~F}$ & 30 & Retrognathia mnd & Anterio open bite & & 38 \\
\hline 3 & $\mathrm{~F}$ & 33 & Retrognathia mnd & Large over jet & & 38 \\
\hline 4 & M & 51 & Retrognathia mnd & Deep bite & Wound infection left side $3 \mathrm{wk}$ postop, PSI removal 6 mo & 37 \\
\hline 5 & M & 26 & Apertognathia & Retrognathia mnd & Artrite activation $12 \mathrm{mo}$, relapse, no reoperation & 36 \\
\hline 6 & M & 42 & Deep bite & Retrognathia mnd. & Late PSI infection right $19 \mathrm{mo}$, PSI removal & 35 \\
\hline 7 & M & 27 & Retrognathia mnd & & & 35 \\
\hline 8 & M & 40 & Deep bite & Retrognathia mnd & Late PSI infection right $7 \mathrm{mo}$, PSI removal & 35 \\
\hline 9 & $\mathrm{~F}$ & 41 & Deep bite & Retrognathia mnd & Reoperation 2 d due to open bite, was TMJ disc replacement & 34 \\
\hline 10 & $\mathrm{~F}$ & 42 & Deep bite & Large over jet & & 32 \\
\hline 11 & $\mathrm{~F}$ & 25 & Anterior open bite & Retrognathia mnd & Open bite due to condyle resorption 21 mo postop & 31 \\
\hline 12 & $\mathrm{~F}$ & 37 & Deep bite & Retrognathia mnd & Wound dehiscence 10 days, resolved spontaneously & 31 \\
\hline 13 & $\mathrm{~F}$ & 42 & Retrognathia mnd & & & 31 \\
\hline 14 & $\mathrm{~F}$ & 36 & Retrognathia mnd & Deep bite & Wound infection right side 3 wk postop, PSI removal 6 mo & 31 \\
\hline 15 & M & 37 & Retrognathia mnd & Anterior open bite & & 28 \\
\hline 16 & $\mathrm{~F}$ & 26 & Retrognathia mnd & & & 28 \\
\hline 17 & $\mathrm{~F}$ & 53 & Deep bite & Retrognathia mnd & & 28 \\
\hline 18 & $\mathrm{~F}$ & 46 & Retrognathia mnd & Deep bite & Wound infection left side 1 wk postop, PSI removal 3 mo & 27 \\
\hline 19 & M & 46 & Deep bite & Large over jet & Wound infection right side 4 wk postop, PSI removal 3 mo & 27 \\
\hline 20 & $\mathrm{~F}$ & 47 & Deep bite & Retrognathia mnd & Due to subjective symptoms PSI removal 16 mo & 26 \\
\hline 21 & $\mathrm{~F}$ & 38 & Retrognathia mnd & Deep bite & & 26 \\
\hline 22 & $\mathrm{~F}$ & 29 & Retrognathia mnd & Deep bite & & 26 \\
\hline 23 & M & 25 & Retrognathia mnd & Deep bite & & 26 \\
\hline 24 & M & 54 & Deep bite & Retrognathia mnd. & & 25 \\
\hline 25 & $\mathrm{~F}$ & 45 & Retrognathia mnd & Large over jet & & 25 \\
\hline 26 & $\mathrm{~F}$ & 32 & Retrognathia mnd & Deep bite & & 24 \\
\hline 27 & $\mathrm{~F}$ & 32 & Retrognathia mnd & Deep bite & & 24 \\
\hline 28 & $\mathrm{~F}$ & 46 & Retrognathia mnd & Large over jet & & 24 \\
\hline
\end{tabular}

Abbreviations: F, female; M, male; mnd, mandible; wk, week; mo, month. 
2017. All PSI patients had visited the clinic within the routine protocol and there were no missing follow-up data within this scope. As a reference, a retrospective cohort of patients $(n=48)$ treated with conventional BSSO, repositioned with wafers and fixated with conventional mini-plates (DePuy Synthes Matrix Orthognathic), was also collected. This cohort was collected from the Helsinki University Hospital patient register from $1^{\text {st }}$ of December 1, 2011 to 30 November 30, 2013. Patients treated with BSSO as the only operation were included in the control group.

In this mini-plate group osteosynthesis was performed using the Matrix Orthognathic system (DePuy Synthes) This used 0.8mm-thick linear or nonlinear plates with two or three screws each side, together with 1.85 -mm-diameter non-locking $6-8 \mathrm{~mm}$ screws. The length of the plate was selected individually for each case, based on the osteotomy gap. See Fig. 1 for details.

In both groups the patients underwent similar surgical protocols, were treated pre- and postoperatively (7-10 days) with $0.12 \%$ chlorhexidine mouth rinse, and received prophylactic intravenous antimicrobial therapy, either with penicillin $\mathrm{G}$, cefuroxime, or ampicillin 15-30 min prior to surgery, according to the clinic protocol. Both groups used postoperative wafers for 4 weeks and were allowed to freely mobilize their jaws postoperatively. They were advised to avoid biting and hard chewing of food for 8 weeks postoperatively.

The collected data, including demographic profile records, reoperations, infections, and soft tissue problems, were analyzed with SPSS software version 22 (IBM Analytics). Non-parametric analysis was performed and the Mann-Whitney U-test was used; a $p$-value of $<0.05$ vas considered significant.

\section{Results}

The demographic data for the PSI and mini-plate cohorts did not differ significantly (gender, $p=0.705$ and age, $p=0.579$ ). The PSI cohort data covered follow-up from 24 to 38 months (average 30 months) and the mini-plate cohort from 12 to 63 months (average 50 months). All PSI patients were followed at the University Hospital Clinic, without dropouts; in the control group only one of the

Table 2

BSSO patients operated with mini-plates.

\begin{tabular}{|c|c|c|c|c|c|c|}
\hline Patient & Gender & Age & Diagnosis 1 & Diagnosis 2 & Wound problems, complications or reoperations & Follow-up (mo) \\
\hline 1 & M & 56 & Deep bite & Retrognathia mnd & & 63 \\
\hline 2 & $\mathrm{~F}$ & 44 & Deep bite & Retrognathia mnd & Swelling left side $8 \mathrm{mo}$, no clear infection, resolved spontaneously & 62 \\
\hline 3 & $\mathrm{~F}$ & 19 & Deep bite & Retrognathia mnd & & 62 \\
\hline 4 & $\mathrm{~F}$ & 45 & Deep bite & Retrognathia mnd & & 62 \\
\hline 5 & $\mathrm{~F}$ & 21 & Anterior open bite & Idiopatic condyle resorption & & 61 \\
\hline 6 & M & 33 & Deep bite & Retrognathia mnd & Plate infection left $2 \mathrm{mo}$, plate removal 4 mo & 59 \\
\hline 7 & $\mathrm{~F}$ & 20 & Retrognathia mnd & Juvenile oligoarthritis & Relapse, Le Fort I osteotomy 36 mo & 59 \\
\hline 8 & M & 49 & Anterior open bite & Osteoarthritis seropositiva & & 58 \\
\hline 9 & $\mathrm{~F}$ & 42 & Deep bite & Retrognathia mnd & & 58 \\
\hline 10 & $\mathrm{~F}$ & 35 & Deep bite & Retrognathia mnd & Wound infection right $1 \mathrm{wk}$, resolved with amoxicillin & 58 \\
\hline 11 & $\mathrm{~F}$ & 49 & Deep bite & Retrognathia mnd & Wound dehiscence left $1 \mathrm{wk}$, soft tissue revision 3 mo & 57 \\
\hline 12 & $\mathrm{~F}$ & 49 & Retrognathia mnd & Distal bite & Plate infection right $1 \mathrm{mo}$, plate removal 3 mo & 56 \\
\hline 13 & M & 50 & Deep bite & Retrognathia mnd & Wound infection left $2 \mathrm{wk}$, plate removal $5 \mathrm{mo}$ & 56 \\
\hline 14 & M & 37 & Deep bite & Retrognathia mnd & & 56 \\
\hline 15 & M & 39 & Deep bite & Retrognathia mnd & & 54 \\
\hline 16 & M & 21 & Anterior open bite & Retrognathia mnd & Relapse, anterior open bite $0.5 \mathrm{~mm}$, no reoperations & 54 \\
\hline 17 & $\mathrm{~F}$ & 42 & Deep bite & Retrognathia mnd & Reoperation 2 days due to open bite, wound opening both sides 10 days & 53 \\
\hline 18 & $\mathrm{~F}$ & 33 & Deep bite & Retrognathia mnd & Wound infection left $2 \mathrm{wk}$, several antibiotics, revision 2 mo & 53 \\
\hline 19 & M & 38 & Deep bite & Retrognathia mnd & Plate infection left $2 \mathrm{mo}$, plate removal $4 \mathrm{mo}$ & 53 \\
\hline 20 & M & 39 & Deep bite & Retrognathia mnd & Wound dehiscence right $1 \mathrm{wk}$, plate removal $3.5 \mathrm{mo}$ & 53 \\
\hline 21 & M & 41 & Scissor bite & & Plate removal 12 mo patient request, no sight of infection & 53 \\
\hline 22 & $\mathrm{~F}$ & 35 & Deep bite & Retrognathia mnd & & 53 \\
\hline 23 & $\mathrm{~F}$ & 25 & Retrognathia mnd & & Wound infection $1 \mathrm{wk}$, resolved with clindamycin and metronidazole & 12 \\
\hline 24 & $\mathrm{~F}$ & 31 & Anterior open bite & Retrognathia mnd & & 52 \\
\hline 25 & $\mathrm{~F}$ & 32 & Deep bite & Distal bite & Plate infection $3 \mathrm{wk}$, plate removal $5 \mathrm{mo}$ & 41 \\
\hline 26 & $\mathrm{~F}$ & 35 & Deep bite & Retrognathia mnd & Wound infection $1 \mathrm{wk}$, resolved with amoxicillin & 52 \\
\hline 27 & M & 28 & Retrognathia mnd & Distal bite & Wound dehiscence left $1 \mathrm{wk}$, resolved with chlorhexidine mouth rinse & 51 \\
\hline 28 & $\mathrm{~F}$ & 18 & Retrognathia mnd & Distal bite & & 51 \\
\hline 29 & $\mathrm{~F}$ & 45 & Deep bite & Retrognathia mnd & & 49 \\
\hline 30 & $\mathrm{~F}$ & 46 & Prognathia $\mathrm{mx}$ & Deep bite & & 49 \\
\hline 31 & M & 51 & Retrognathia mnd & & & 48 \\
\hline 32 & $\mathrm{~F}$ & 49 & Deep bite & Retrognathia mnd & Swelling left side 2 mo, no clear infection, resolved spontaneously & 48 \\
\hline 33 & $\mathrm{~F}$ & 20 & Anterior open bite & Retrognathia mnd & Infection $10 \mathrm{~d}$, revision $2 \mathrm{wk}$, late plate infection $23 \mathrm{mo}$, plate removal & 47 \\
\hline 34 & $\mathrm{~F}$ & 42 & Deep bite & Retrognathia mnd & Wound infection $10 \mathrm{~d}$, resolved with kefalexin & 46 \\
\hline 35 & $\mathrm{~F}$ & 34 & Retrognathia mnd & Anterior open bite & Osteosynthesis failure $4 \mathrm{~d}$, reoperated & 46 \\
\hline 36 & $\mathrm{~F}$ & 39 & Scissor bite & Deep bite & & 46 \\
\hline 37 & $\mathrm{~F}$ & 35 & Deep bite & Retrognathia mnd & Wound infection both sides, plate removal 5 mo & 45 \\
\hline 38 & $\mathrm{~F}$ & 45 & Deep bite & Retrognathia mnd & & 45 \\
\hline 39 & $\mathrm{~F}$ & 23 & Anterior open bite & Retrognathia mnd & Relapse 18 mo, no reoperation & 45 \\
\hline 40 & $\mathrm{~F}$ & 36 & Deep bite & Retrognathia mnd & Late plate infection $17 \mathrm{mo}$, plate removal & 45 \\
\hline 41 & M & 25 & Deep bite & Retrognathia mnd & & 44 \\
\hline 42 & $\mathrm{~F}$ & 33 & Distal bite & Deep bite & & 43 \\
\hline 43 & $\mathrm{~F}$ & 50 & Deep bite & Retrognathia mnd & & 43 \\
\hline 44 & $\mathrm{~F}$ & 22 & Anterior open bite & Cross bite & & 42 \\
\hline 45 & $\mathrm{~F}$ & 26 & Deep bite & Retrognathia mnd & & 42 \\
\hline 46 & $\mathrm{~F}$ & 50 & Deep bite & Retrognathia mnd & & 42 \\
\hline 47 & M & 44 & Deep bite & Retrognathia mnd & & 41 \\
\hline 48 & $\mathrm{~F}$ & 52 & Deep bite & Retrognathia mnd & & 39 \\
\hline
\end{tabular}

Abbreviations: F, female; M, male; mnd, mandible; wk, week; mo, month; mm, millimeter; mx, maxilla. 
48 patients dropped out after 12 months follow-up because the postoperative orthodontics were performed outside the hospital. The individual patient data, including postoperative wound and soft tissue problems, as well as reoperations, are presented in detail in Table 1 for PSI patients and in Table 2 for the conventional miniplate patients.

Soft tissue problems were divided to three categories: wound dehiscence, early infection (0-4 weeks), and late infection (after 4 weeks). If pus was detected, or the wound problem so severe that the clinician administered antibiotic therapy, this was classified as infection. The groups did not differ statistically with regards postoperative wound problems or infections $(p=0.248)$, hardware removal $(p=0.395)$, or reoperations $(p=0.847)$. In general, both groups developed a surprisingly high number of postoperative wound problems (eight out of 28 for the PSI group and 19 out of 48 for the control group). When the data were analyzed by gender, hardware removal was significantly more common in females $(p=0.031)$, however, the number of female postoperative infections or wound problems was not significantly higher $(p=0.485)$. The reason for this difference in asymptomatic plate removal between the genders remains unclear.

\section{Discussion}

PSIs are an ideal way to achieve faster and more precise surgery. For advancement of the maxilla with Le Fort osteotomy their use has been proven to be accurate, even without wafers (Heufelder et al., 2017). The repositioning of bone segments in the mandible can be achieved without wafers. For condylar segment positioning both bone- and dentition-supported drill guides together with PSIs have been used (Abdel-Moniem Barakat et al., 2014; Suojanen et al., 2017). However, in our previous study the CAD/CAM drill guide system was not reliable enough to be recommended for use without wafers (Suojanen et al., 2017).

The PSIs are usually produced from titanium alloy using similar methods to those used almost a decade ago in reconstructive surgery. Some follow-up data for the use of PSIs already exist and rather high postoperative complication rates have been reported (Stoor et al., 2017). We have previously reported that PSIs lead to similar postoperative infection profiles but fewer reoperations due to a malocclusion, when compared with conventional mini-plates (Suojanen et al., 2018). However, to our knowledge, no follow-up data on the use of PSIs in BSSO exist to date.

An ideal implant is both biocompatible and antibacterial, and these properties are linked to both the chemical composition as well as the tooling of the implant. Several physical and chemical techniques and manipulations have been studied with the aim of improving surface characteristics of medical implants. The ultimate goal is to facilitate bio-integration and prevent initial bacterial adhesion at the same time (Veerachamy et al., 2014). Formation of biofilms starts from initial infection, either during surgery or later after wound problems. In both cases graft material is covered with biofilm, which leads to the clinically manifested postoperative infection. This is a four-step process, starting with initial attachment of bacteria to the implant surface, followed by multiplication and aggregation of bacteria into multilayer structures. This leads to consecutive biofilm formation, eventually resulting in detachment of planktonic bacterial cells from the biofilm community into the surrounding tissues (Arciola et al., 2015). Design of CAD/CAM implants may be a compromise between susceptibility to bacterial infection and biocompatibility, and to date very few clinical data exist on this. Infection rates in the mandible are generally higher than in the maxilla (Davis et al.,
2017). Wound problems were also surprisingly common in both of our study groups.

\section{Conclusions}

The follow-up data in this study suggest that CAD/CAMproduced titanium PSIs do not differ in terms of their localized long-term complication profile when compared with conventional mini-plate systems after bilateral sagittal split osteotomy.

\section{Financial support}

This work was financially supported by the Emil Aaltonen Foundation, the Finnish-Norwegian Medical Foundation, the Finnish Medical Foundation, the Paulo Foundation, Helsinki University Hospital Funds, and the Academy of Finland (reference no. 299749).

\section{Conflicts of interest}

Authors JS, ZH, JL, and PS have participated in congresses where attendance fees were in part or in total supported by DePuySynthes or KLS-Martin.

\section{Acknowledgements}

This work was financially supported by the Emil Aaltonen Foundation, the Finnish-Norwegian Medical Foundation, the Finnish Medical Foundation, the Paulo Foundation, Helsinki University Hospital Funds and the Academy of Finland (reference no. 299749).

\section{References}

Abdel-Moniem Barakat A, Abou-ElFetouh A, Hakam MM, El-Hawary H, AbdelGhany KM: Clinical and radiographic evaluation of a computer-generated guiding device in bilateral sagittal split osteotomies. J Craniomaxillofac Surg 42(5): e195-e203, 2014

Arciola CR, Campoccia D, Ehrlich GD, Montanaro L: Biofilm-based implant in fections in orthopaedics. Adv Exp Med Biol 830: 29-46, 2015

Davis CM, Gregoire CE, Davis I Steeves TW: Prevalence of surgical site infections following orthognathic surgery: a double-blind, randomized controlled trial on a 3-day versus 1-day postoperative antibiotic regimen. J Oral Maxillofac Surg 75(4): 796-804, 2017

Epker B: Modifications in the sagittal osteotomy of the mandible. J Oral Surg 35: 157-159, 1977

Gander T, Bredell M, Eliades T, Rucker M, Essig H: Splintless orthognathic surgery: a novel technique using patient-specific implants (PSI). J Craniomaxillofac Surg 43: 319-322, 2015

Heufelder M, Wilde F, Pietzka S, Mascha F, Winter K, Schramm A, et al: Clinical accuracy of waferless maxillary positioning using customized surgical guides and patient specific osteosynthesis in bimaxillary orthognathic surgery. J Craniomaxillofac Surg 45(9): 1578-1585, 2017

Mazzoni S, Bianchi A, Schiariti G, Badiali G, Marchetti C: Computer-aided design and computer-aided manufacturing cutting guides and customized titanium plates are useful in upper maxilla waferless repositioning. J Oral Maxillofac Surg 73: 701-707, 2015

Stoor P, Suomalainen A, Mesimäki K, Kontio R: Rapid prototyped patient specific guiding implants in critical mandibular reconstruction. J Craniomaxillofac Surg 45(1): 63-70, 2017

Suojanen J, Leikola J, Stoor P: The use of patient specific implants in orthognathic surgery - a series of 32 maxillary osteotomy patients. J Craniomaxillofac Surg 44(12): 1913-1916, 2016

Suojanen J, Leikola J, Stoor P: The use of patient-specific implants in orthognathic surgery: a series of 30 mandible sagittal split osteotomy patients. J Craniomaxillofac Surg 45(6): 990-994, 2017

Suojanen J, Järvinen S, Kotaniemi KVM, Reunanen J, Palotyie T, Stoor P, et al: Comparison between patient specific implants and conventional mini-plates in Le Fort I osteotomy with regard to infections: no differences in up to 3-year follow-up. J Craniomaxillofac Surg. https://doi.org/10.1016/j.jcms.2018.07.011, 2018

Veerachamy S, Yarlagadda T, Manivasagam G, Yarlagadda PK: Bacterial adherence and biofilm formation on medical implants: a review. Proc Inst Mech Eng $\mathrm{H}$ 228(10): 1083-1099, 2014 